\title{
BMJ Open Cross-sectional study on medicinal products without commercial interest (MPWCI) in the Spanish market
}

\author{
Emili Esteve Sala, ${ }^{1,2}$ Fátima Montes Barroso, ${ }^{1}$ Elvira Bel Prieto, ${ }^{2}$ \\ Josep María Suñé Negre ${ }^{2}$
}

To cite: Esteve Sala E, Montes Barroso F, Bel Prieto E, et al. Cross-sectional study on medicinal products without commercial interest (MPWCI) in the Spanish market. BMJ Open 2019:9:e023054. doi:10.1136/ bmjopen-2018-023054

- Prepublication history and additional material for this paper are available online. To view these files, please visit the journal online (http://dx.doi. org/10.1136/bmjopen-2018023054).

Received 2 April 2018

Revised 29 October 2018

Accepted 5 November 2018

Check for updates

(C) Author(s) (or their employer(s)) 2019. Re-use permitted under CC BY-NC. No commercial re-use. See rights and permissions. Published by BMJ.

${ }^{1}$ Technical Department, Farmaindustria, Madrid, Spain ${ }^{2}$ Pharmacy and Pharmaceutical Technology, and Physical Chemistry, Faculty of Pharmacy and Food Sciences, University of Barcelona, Barcelona, Spain

Correspondence to

Mr Emili Esteve Sala; eesteve@farmaindustria.es

\section{ABSTRACT}

Objective To confirm that there is a defined group of products to be protected in the Spanish therapeutic arsenal known as 'medicinal products without commercial interest' (MPWCl) and propose the adoption of legal measures aimed at avoiding, or reducing, the lack of supply of said products.

Design A cross-sectional study of proposed MPWCI based on a survey. The Spanish Agency of Medicines and Medical Devices (AEMPS) was asked for a list of presentations of medicines in order to identify those whose lack could have an impact on welfare.

Setting A search on the AEMPS website and a survey conducted among 44 companies belonging to Farmaindustria has allowed for the development of a proposal list of presentations that should continue to be marketed in Spain.

Results Products proposed as MPWCI are old ( $50 \%$ of them have an authorisation of more than 50 years) and are developed by active substances of chemical origin, parenterally administered much more frequently than the rest of the general market (44\%vs6.6\%, respectively). Unlike oral forms, injectable forms require adequate manufacturing facilities to guarantee the quality and sterility of the product, which naturally increases the cost of the product whose price is low or obsolete. The company experts have not valued the current price revisions as a sufficient enough mechanism to change the consideration of these medicines with respect to the interest on the part of some Marketing Authorisation Holders to maintain their commercialisation.

Conclusions As shown in the results, an upward revision of prices is necessary to contribute to the permanence of these presentations in the market, although some experts do not consider the current price revisions satisfactory enough to maintain these presentations in the market. Therefore, a specific regulation seems necessary to ensure the continuity on the market of these proposed products.

\section{INTRODUCTION}

Spanish legislation refers to 'medicinal products without commercial interest' (hereon in MPWCI) as those where there is an absence, or shortfall, of supply within the Spanish market, yet are still required to treat certain diseases or pathologies.

\section{Strengths and limitations of this study}

This is the first article to propose that a group of products be considered as MPWCI, originating from a list of products identified by the Spanish Agency of Medicines and Medical Devices (AEMPS), taking into account the opinion of a group of experts from the Marketing Authorisation Holders.

- The analysis of the products to be considered as medicinal products without commercial interest (MPWCl) has been strengthened by the results of a survey that allows conclusions to be drawn about the need to typify and regulate MPWCI in Spain.

- The results of the survey are limited to those products belonging to companies associated to Farmaindustria. Future studies could be expanded and include the opinions of healthcare professionals or experts from other fields, such as university.

- The data from the survey reflect the situation at a given time. The pharmaceutical sector situation is constantly changing, in a way that the number of presentations affected could vary depending on regulatory decisions that may be adopted.

There are several causes which can affect the initial marketing authorisation conditions during a medicine's life cycle, and this can lead to an absence or a lack of supply. Somes examples of these causes would be, the existence of other competitors, new implementation of regulatory requirements, ${ }^{1}$ additional restrictions derived from pharmacovigilance, ${ }^{2}$ entries of generic medicinal products $^{3}$ (hereon in only referred to as 'products') or, simply, a decrease in demand due to obsolescence.

All of these circumstances ultimately affect marketing viability for certain products, leading to their disappearance from a market which is constantly changing. However, when this situation affects products that are still crucial for treating certain diseases, the lack of availability poses a conflict that has an effect on patients and healthcare professionals, reducing treatment options and 
damaging the pharmaceutical industry's image because the Marketing Authorisation Holders (MAH) is blamed for the fact that the medicine can no longer be used by patients and health professionals.

The fact that it is still necessary to guarantee the availability of certain products and, more precisely some presentations (defined hereon in as specific strength, pharmaceutical form and content in weight, volume or units of dosage), denotes that further development of Spanish regulation seems necessary in order to ensure the commercialisation of these products with high healthcare interest but low economical interest.

In accordance with current Spanish legislation, and in order to ensure the supply of products, the government can adopt special measures in relation to its manufacture, import, distribution and dispensing. In particular, and in the case of MPWCIs, in addition to the above-mentioned measures, Spanish legislation allows those relating to the economic and fiscal regime in favour of such products. ${ }^{4}$

In this paper, we aim to answer whether there is a group of marketed products that could be considered MPWCI, a legal category of medicines described but not developed in Spanish legislation. An identification of these types of products is suggested, the description of their characteristics, the main causes that threaten their marketing viability and several considerations regarding the need to develop regulations for this matter in Spain.

Once we had confirmed and studied the presence of a group of MPWCI in Spain, we considered the need of adopting a legislative development to protect these products' marketing viability. As a matter of fact, the absence or lack of supply of essential medicines in the Spanish market could represent a great issue for the health system, healthcare professionals and patients.

\section{Marketing conditions}

The marketing authorisation (herein MA) establishes the main marketing conditions of the product's authorisation throughout its life cycle. The MA includes, among other elements, the summary of product characteristics,

\section{A Exclusive situation (patented)}

- Modification of the authorization conditions (e.g. new indications)

- Pharmacovigilance restriction ${ }^{11,12}$

- Competitors in the same therapeutic area ${ }^{13}$

- Discontinuation

- Price revision ${ }^{14}$

- Supply issues ${ }^{15-18}$

- Serialization ${ }^{19}$ which gathers all the therapeutic conditions of use, such as authorised indications or contraindications. The MA is granted, on one side, by the European Commission for those cases in which products are authorised by centralised procedure ${ }^{5}$ and by the member states of the European Union for the remaining the cases. ${ }^{6}$ In Spain, the competent authority for issuing marketing authorisations is the Spanish Agency of Medicines and Medical Devices (AEMPS) ${ }^{7}$

Once the product is authorised, the Spanish competent authorities make a decision about its price and reimbursement regardless of the procedure for which the medication was authorised. In Spain, the procedure includes the participation of the Inter-Ministerial Pharmaceutical Pricing Commission (CIPM). ${ }^{8}$ When this process has ended, the MAHs communicate to AEMPS the intention to effectively market the drug, requesting its inclusion in the official Presentation Catalogue of the Pharmaceutical Provision of the National Health System. From the moment of the product's publication in the presentation catalogue, retail products can then be marketed immediately, but in the case of products in hospitals, the MAH must frequently manage additional procedures for local access in the different regions. ${ }^{9} 10$

The initial conditions of authorisation change throughout the life cycle of the product and can be divided into two stages: (1) when the original product is in an exclusive situation; (2) when the protection offered by both the patent and the data protection has expired. Figure 1 summarises the main causes that modify the conditions of the initial authorisation of the original products. $^{311-22}$

\section{OBJECTIVES}

1. Confirm that there is a defined group of products to be protected in the Spanish therapeutic arsenal (MPWCI proposed).

2. Propose the adoption of legal measures aimed at avoiding, or reducing, the lack of supply of said products.

\section{B Situation with competitors (non-} patented)

- Generic medicine competition

- Deduction to the NHS increases to $15 \%$, once the IP rights are expired and the product is not included in the Reference Price System ${ }^{20}$.

- Alignment of a lower price through the Homogeneous Group System ${ }^{3,21}$

- Price reduction by applying the Reference Price System 22

Figure 1 Causes that modify the authorisation conditions: (A) causes that affect all commercialised products (patented or not), (B) causes that only affect those products without patent protection or data protection. NHS, National Health Service. 


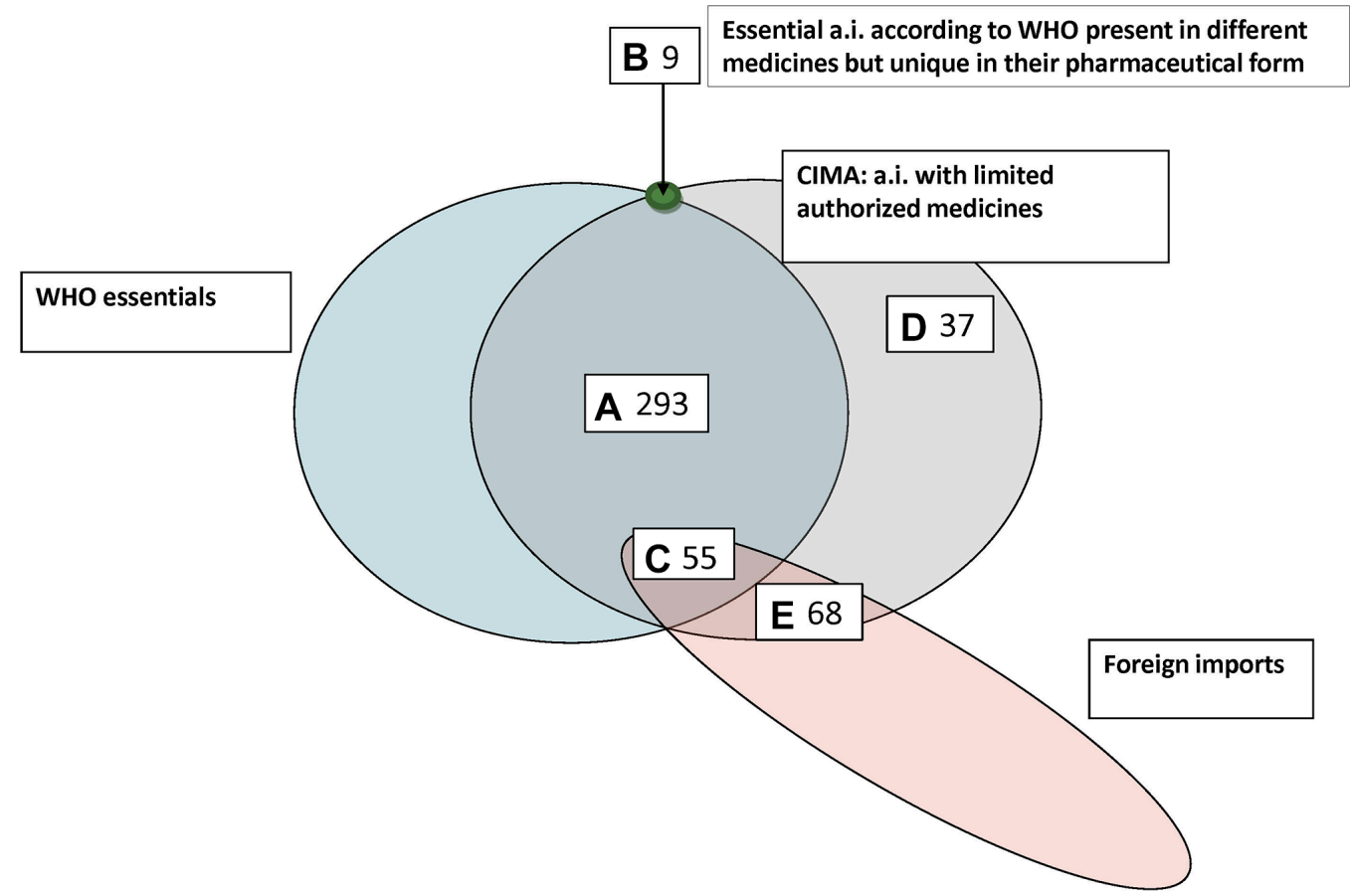

Figure 2 Distribution of essential products for the Spanish market. Source: AEMPS.

\section{METHODS}

\section{Data collection}

The Spanish Agency of Medicines and Medical Devices (AEMPS) was asked for a list of medicine presentations in order to identify, within the presentations of medicines marketed in Spain, those whose lack could have an impact on the National Health Service (NHS) and patients. The list provided considered those medicines at risk and whose lack could have an impact on healthcare at a specific time (January 2017 in this instance). It also noted the necessary safeguards that have a list of medicines whose clinical use is contingent to multiple factors that may change over time.

This list contained 462 products, ordered by authorisation number in the case of products registered in Spain and with other registration numbers in the remaining cases.

The list had been developed by AEMPS in accordance with the following criteria (see figure 2):

A comparison of WHO's Essential Medicines List (EML) and a list of products authorised in Spain, stored in CIMA (Online Medicine Information Centre), selecting the cases where, for each essential active substance, only one or two medicinal products were authorised. Those cases that have two or more therapeutic alternatives authorised and marketed in Spain are not considered to be at risk.

Those cases that have two or more therapeutic alternatives authorised and marketed in Spain are not considered to be at risk and were, therefore, removed from the list. The resulting list had a total of 357 products which were divided as follows: a. 293 products commercialised in Spain with essential active substances according to the EML.

b. 9 products commercialised in Spain with a unique pharmaceutical form and contain essential active substances according to the EML.

c. 55 authorised, but not commercialised, products with essential active substances according to the EML (imported through Foreign Medicinal Products Service).

Some products that were not considered essential by WHO but are still essential in the Spanish market were added to the list (a total of 105 products, containing 84 active ingredients). The AEMPS considers that in addition to WHO's list of essential medicines, in Spain, it is necessary to maintain the commercialisation of other medicines (or of certain dosages or pharmaceutical forms of administration) since they constitute the only authorised presentation in Spain for a certain indication. The MAHs have applied this same criterion.

d. 37 products commercialised in Spain.

e. 68 authorised but not commercialised products in Spain (imported through Foreign Medicinal Products Service).

This initial relationship was subjected to the process outlined in figure 3 and is described below.

AEMPS provided a list of 462 products considered to be at risk, whose shortage could have an impact on healthcare, which were then divided into two groups in order to be able to consult the companies.

1. List of products belonging to companies associated to Farmaindustria (258 records)

2. List of products belonging to other companies (204 records) 


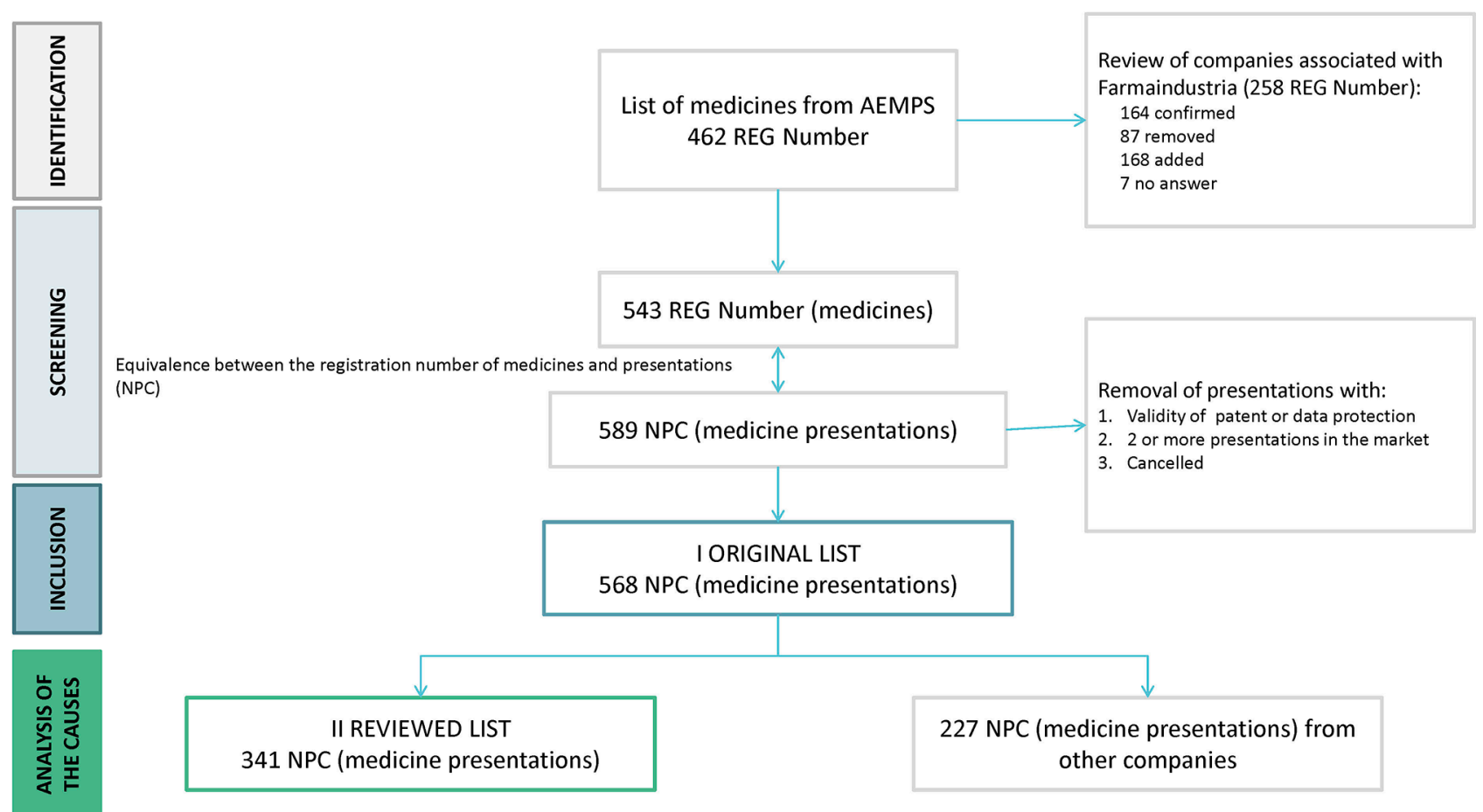

Figure 3 Diagram of the review carried out for the different medicinal product presentation lists whose viability of commercialisation has been reviewed in the present list. REG Number: Registration Number. NPC, National Product Code.

The list of products was divided up accordingly and distributed to experts from the corresponding affected company (associated to Farmaindustria) together with an assessment questionnaire. It is important to point out that the questionnaire reflected the experts' opinions and that it did not involve an official or binding response from the MAH.

The questionnaire was created to obtain the following answers:

1. Confirm if the products in the reviewed list from the company could effectively identify the products to be protected in order to ensure their continuity in the market.

2. Remove those products that, in the original list, despite being considered at risk of commercialization by AEMPS, did not present a threat either in the viability or in the supply, according to an expert's judgement

3. Add new products that, even though not having been considered at risk of commercialization by AEMPS, do still pose a threat to viability and supply, according to an expert's judgement

This consultation was restricted to MAH experts because they are the ones who can best assess the two reasons addressed in the survey and are characteristic of the companies' internal knowledge: (1) derived from production (raw material supply, manufacturing problems, obligation to serialise, delays in the processing of variations) or (2) derivatives of economic regulation that affect MAH (reference prices, price revisions).

From this, a list of products valued by experts from companies associated to Farmaindustria was obtained, which, with the confirmations (164), additions (168), no answers (7) and deletions (87), went from 258 to 339 records.

The list of products reviewed by company experts associated to Farmaindustria, together with the list without further validation $(339+204=543$ records $)$ needed, for the purpose of better research, a conversion from products (REG Number) to presentations (as defined on page 1), since the commonly used databases (IMS, BOt Plus, Catalogue from Farmaindustria) use the presentation identified by its National Product Code.

The list of 543 products increased to 589 presentations because, as expected, some product records are marketed in several presentations.

A new revision was carried out on the list of 589 presentations, and the following categories were removed:

1. Presentations that still have market exclusivity (due to patent or data protection), considering that these products, although they had a critical therapeutic role in case of shortages, were not part of the products to be protected due to the lack of interest in their commercialisation by pharmaceutical companies.

2. The presentations of products that have two or more generic or competitors marketed, considering that the negative effects of non-commercialisation of the original product could be remedied by the commercialisation of generics or competitors, and vice versa.

3. The suspended or revoked presentations of products still authorised in other presentations, which are normally imported as foreign medication.

The resulting list, which is named 'original list', contained 568 presentations. The 568 presentations were 
listed as authorised and marketed in the database (CIMA) of AEMPS.

Regarding this original list, its distribution by MA longevity, Anatomical, Therapeutic \& Chemical (ATC) group and route of administration, with respect to the general market, has been considered. The active substances in this group of presentations have also been listed.

Out of the presentations from the initial list, 341 correspond to companies associated to Farmaindustria, which we have called 'reviewed list'.

Regarding the reviewed list, there is additional information obtained by the responses to a questionnaire to assess the reasons for a possible lack of viability due to production, economic causes, or both.

Although the ideal would have been to consult experts from all the MAHs of the products included in the initial list, the difficulties in submitting the questionnaire, as well as obtaining and analysing the corresponding answers, have resulted in circumscribing this list to the evaluation of the experts from the field of pharmaceutical regulation in the form of a technical working group of Farmaindustria (RTM Group).

In relation to the causes of a possible non-permanence in the market of a certain presentation derived from production, the questionnaire offered the following possibilities:

1. The lack, or shortage, of raw material supply, mainly due to the fact that the MAHs of this type of product with limited consumption and outdated prices may have problems in finding a guaranteed manufacturer/ supplier of the active substance.

2. Problems in manufacturing derived from the industrial repositioning in the manufacturing priorities of these products and contract manufacturing in some cases.

3. The obligation to include safety features (unique identifier and an anti-tampering device) on the packaging of certain products for human use for the purposes of allowing their identification and authentication, as a consequence of the application of Commission Delegated Regulation (EU) 2016/161 that may be a subsequent cause and make a certain presentation unfeasible.

4. The delays in the variations procedure in some cases (manufacture or control changes in active substance or finished product).

5. Other causes different from the previous ones.

In relation to the causes of a possible non-permanence in the market of a certain presentation derived from economic regulation, the questionnaire offered the following possibilities:

1. The application of the Reference Price System (RPS), since it may affect certain presentations with a small content of active substance and consequently very low price (eg, low dosages, oral solutions, among others) that do not have a marketed competitor but that are affected by the lower cost per treatment, per day of the group. In particular, it asked whether the options to remove the threat of lack of viability in commercialisation would mean the exclusion of the presentation of the RPS or the application of the so-called weighted reference price (applied to those presentations with special dosages, or which are indicated for serious pathologies, or whose prices have been revised by the CIMP in the last 2 years due to their low profitability), or if there was any other suggested option.

2. The price of the presentation. The intervened price of products financed by the NHS may become obsolete, especially in the case of old marketing authorisations. The questionnaire asked whether the threat to stay in the market was due to a lack of price viability or due to a lack of price viability even after having been revised upwards. It also contemplated whether the continuity in commercialisation was influenced both by the price and by the lack of interest to continue by the marketing authorisation holder.

3. Other causes different from the previous ones.

\section{Patient and public involvement}

Neither patients nor the public were involved in this study.

\section{RESULTS}

Original list

The original 568 presentations were studied in various areas.

\section{By active substance}

The active substances of the proposed initial MPWCI relationship are shown in online supplementary annex 1. For the purposes of this classification, if two or more presentations contain the same active substance, the active substance only appears once in the table. Likewise, the different salts and derivatives of an active substance are considered as the same active substance. The active substances that are formulated as a single ingredient appear with their name. If they are part of an association of two or more active substances, the figure shows the number of active substances and the names of the medicinal products combination at a fixed dose.

\section{Date of the marketing authorisation}

Products whose lack of commercialisation could have an impact on welfare are old. More than $75 \%$ of the products in the list were authorised in the last century and almost $50 \%$ of the products considered essential have an authorisation of more than 50 years.

The comparison of the age of the initial MPWCI with the rest of the products in the reimbursable market ${ }^{23}$ shows that more than three-quarters of the total medicines proposed as MPWCI $(76.27 \%)$ are authorised before the year 2000. In the case of the remaining presentations within the reimbursable market, most of the commercialised presentations $(82.07 \%)$ have a marketing authorisation after the year 2000 . 


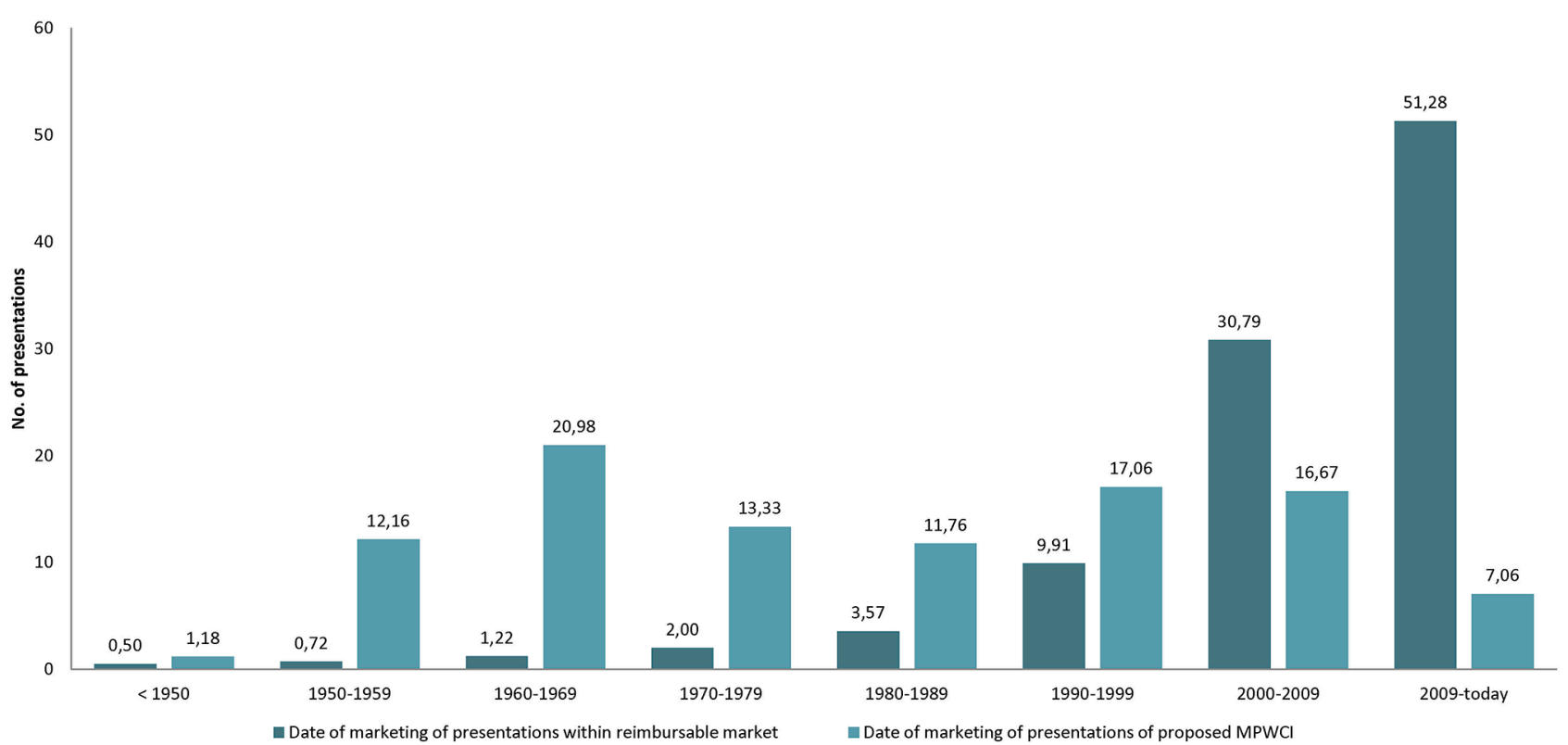

Figure 4 Distribution of product medicinal products without commercial interest (MPWCl) presentations (original list) studied due to the age of the marketing authorisation in Spain compared with the rest of the reimbursable presentations in Spain.

Predictably, most of the old products marketed in Spain before the year 2000 belong to this category of products to be protected (see figure 4).

\section{Therapeutic group}

The distribution by therapeutic groups, according to the ATC classification has been another aspect taken into consideration in the initial list of the proposed MPWCI. The comparison between the presentations of products in the reimbursable market (IQVIA data) in relation to the initial list of MPWCI shows differences in the distribution of medicines by therapeutic groups. For example, in the rest of presentations within the reimbursable market, the antineoplastic and immunomodulating agents reach $3 \%(2.92 \%)$ while in the MPWCI group, this proportion reaches $13 \%$ (12.94), which could indicate that in certain areas (antiparasitic, anti-infectives, ophthalmic, blood-derived products or certain hormones), those products continue to play a therapeutic role (see figure 5).

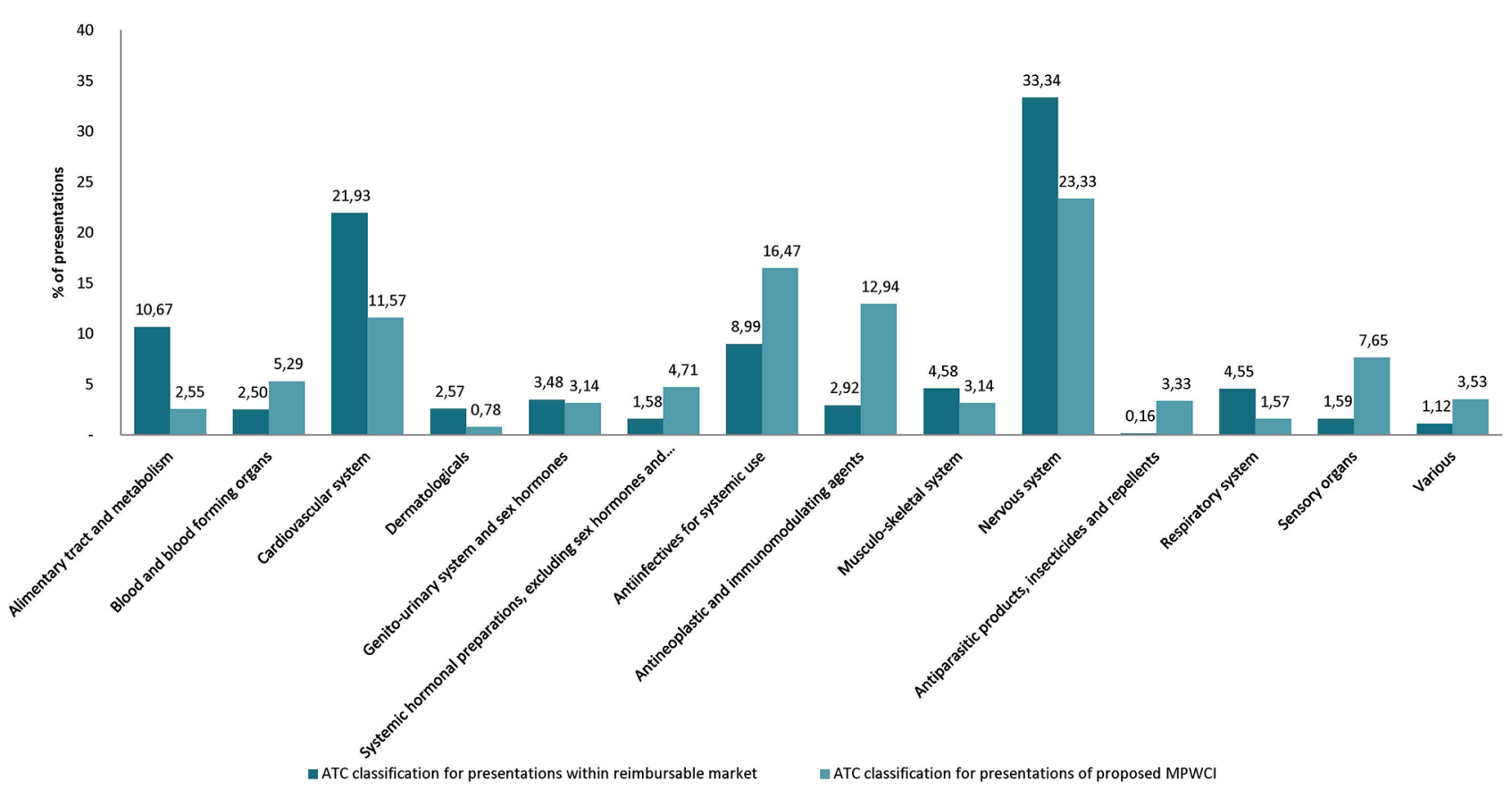

Figure 5 Distribution of authorised product presentations in Spain by therapeutic group comparing medicinal products without commercial interest (MPWCl) (original list) to the rest of the reimbursable presentations. ATC, Anatomical, Therapeutic \& Chemical. 


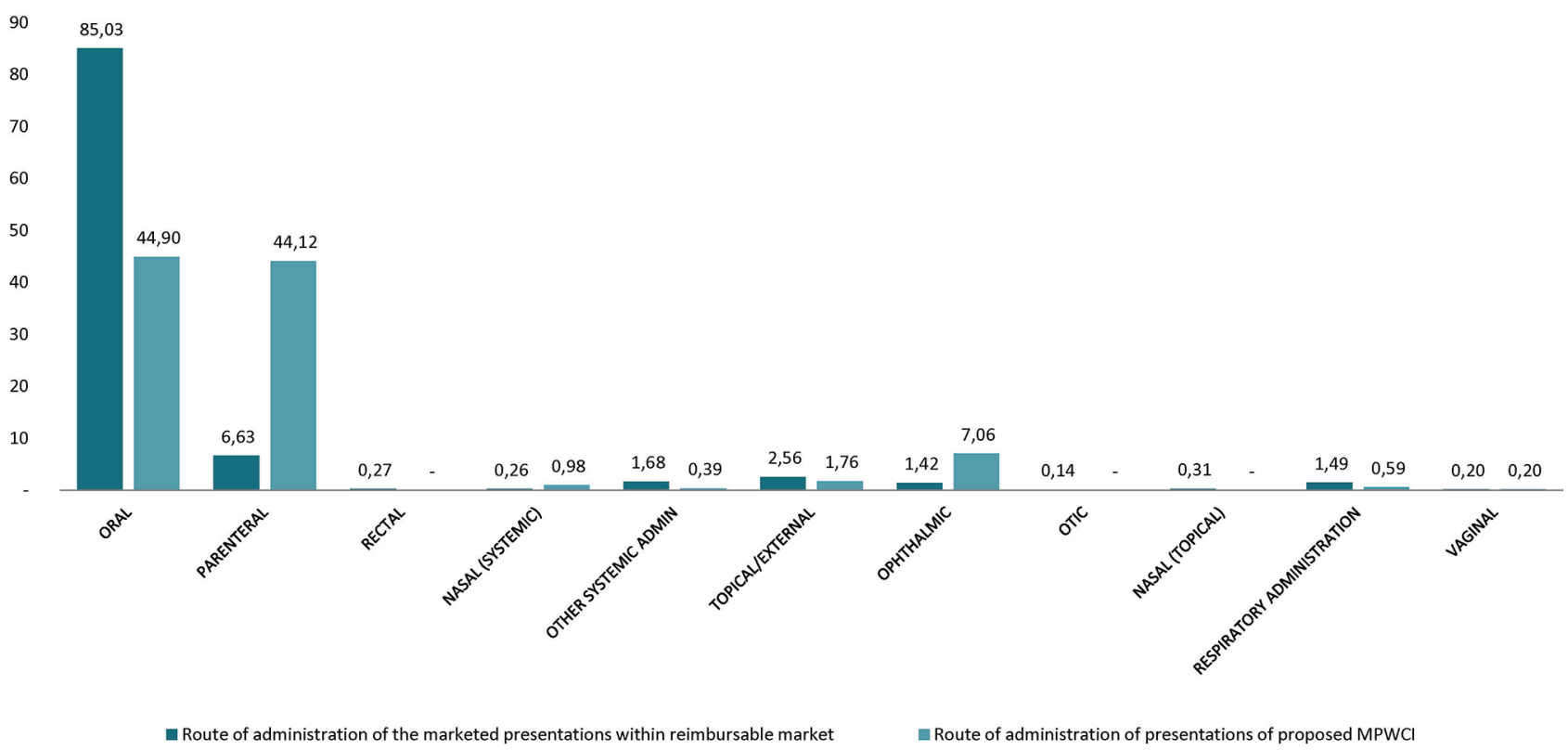

Figure 6 Distribution of authorised product presentations in Spain by administration route comparing medicinal products without commercial interest (MPWCI) (original list) to the rest of the reimbursable presentations.

\section{Route of administration}

In the case of the proposed MPWCIs, the results show a more than remarkable concentration of these products of interest in certain routes of administration, with a very different distribution compared with the reimbursable market (IMS data). Although expected, it is striking, with a high proportion of injectable forms in the case of MPWCIs proposed with $44.12 \%$ of the total presentations of the category, compared with only $6.63 \%$ of presentations in the reimbursable market (IMS data). Similarly, this occurs in the ophthalmic forms in which the proposed MPWCIs represent $7 \%$ of the total sample compared with $1.42 \%$ of the presentations in the reimbursable market (IMS data) (see figure 6).

\section{REVIEWED LIST}

As mentioned above, the questionnaire was sent to experts from 44 companies belonging to Farmaindustria. Thirty-seven responses were received from the experts of these companies, representing $84 \%$ of those consulted. The data collection was carried out from February to July 2017.

These company experts from these companies indicated that they are not concerned by reasons only resulting from production. For only $4 \%$ of the cases, the continuity of the strategic presentations could be at risk of permanence in the market for reasons exclusively relating to production. The isolated economic aspects have a greater relevance, since they represent $20 \%$ of the assumptions considered. This percentage rises to $76 \%$ if we consider both causes, that is, those derived from regulation and production.

For some experts, the alignment of the increasing difficulties to obtain a regular supply of active substances or of intermediate products under suitable conditions of price and service, the requirements of the regulation for the processing of the registry variations relative to the places of manufacture and the modifications that the serialisation of products will entail can jeopardise the viability in the marketing of certain presentations (figure 7).

\section{Causes derived from production}

In the experts' opinion, the lack, or shortage, of supply of raw materials constitutes a problem for the viability in the supply of the proposed MPWCI ( $42 \%$ responses). The other main concern is about procedures ( $42 \%$ responses) that can delay, or even stop, the supply of a particular product due to the serialisation rules that involve modifying the conditioning lines of many companies to incorporate both antitamper devices and the unique identifier

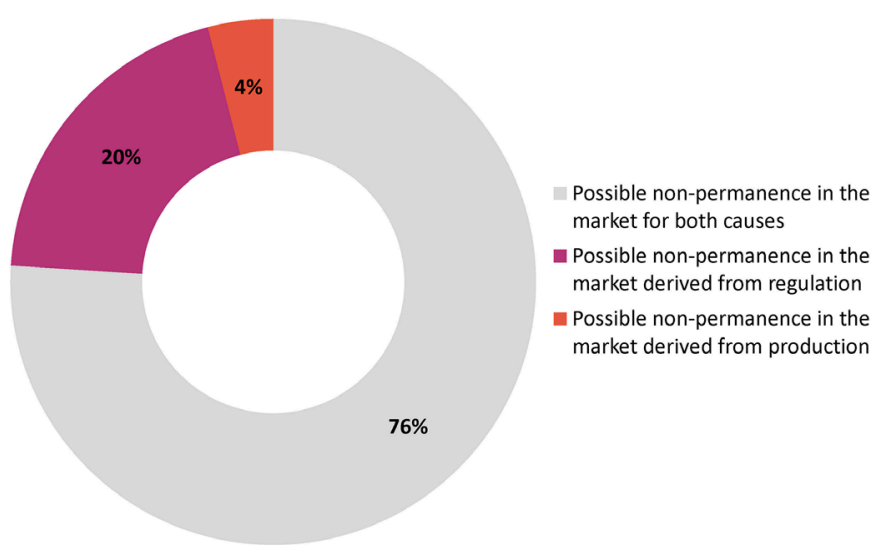

Figure 7 Main causes that may lead to a possible nonpermanence of medicinal products without commercial interest (MPWCI) (reviewed list) presentations in the Spanish market. 


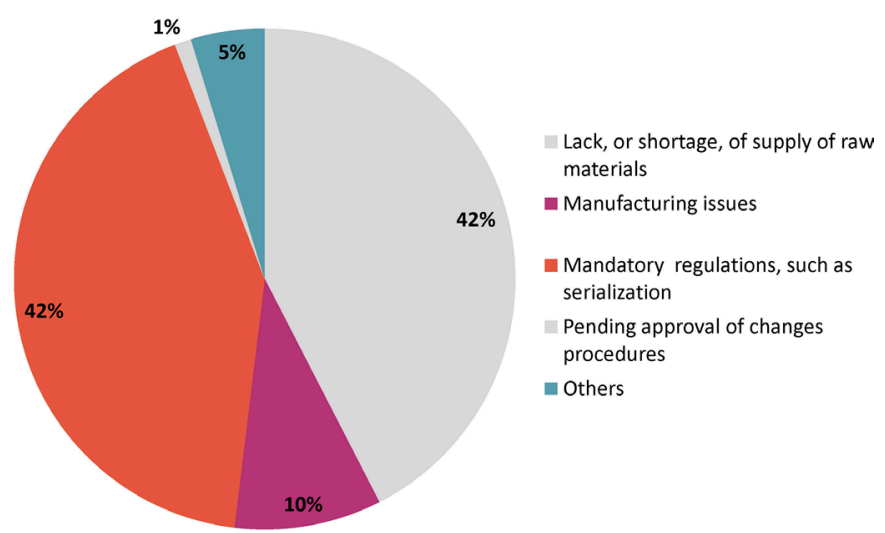

Figure 8 Main causes related to production that may lead to possible non-permanence of medicinal products without commercial interest (reviewed list) presentations in the Spanish market.

of each of the containers affected by Delegated Regulation (EU) 2016/161 (figure 8).

Another cause refers to the manufacturing issues $(10 \%$ responses), especially in case of modification of the production strategy of some products in a certain manufacturing plant. In the segment 'others' (5\% responses), the main threats to the permanence of these presentations in the market are: a difficulty in updating the registration dossier (which could be critical BREXIT scenario), the absence of a raw material in a product on a global scale, the cost of the administration device regarding the price of the medicine, the complexity of the manufacture or the lack of a manufacturer, especially in the case of products that are marketed in only a few countries (sometimes only in one single country) (see figure 8 ).

\section{Causes derived from economic regulation}

In the experts' opinion, the low prices of the products studied would be the first factor (55.99\% responses) in causing a threat to the continuity in commercialisation. In this case, the products are not affected by the RPS since they are products that have no marketed competitor and, therefore, the reference group has not been established.

In the case of products with a competitor RPS, they affect all the presentations included in said group, which are subject to a price review every year. According to the answers obtained (38.48\% responses), the feasibility for minority consumption presentations in these groups, which contains active substances within the proposed MPWCI, is at risk.

Experts have responded to other causes $(4.38 \%$ responses) also, including the absence of regulatory development for the transfer of MAH, as envisaged by RD 1345/2007 which, in Spain, regulates the registration of products or the risk of an avoidable national shortage if the presentations were to be subject to an exceptional prior notification, regulated in order to be sent to another member state ${ }^{24}$ (see figure 9).

In relation to the presentations included in the RPS, the solution considered most appropriate to guarantee the permanence in the market of these presentations would be their exclusion from the system (84\%). The option of reducing the drop in prices through the application of weighted prices is a minority one $(7 \%)$.

As mentioned, many of the proposed MPWCI presentations are unique $(77 \%)$ if we consider their pharmaceutical form and dosage (see figure 10).

With regards to the price of products, $85 \%$ of the total of responses indicates that the price would not be viable

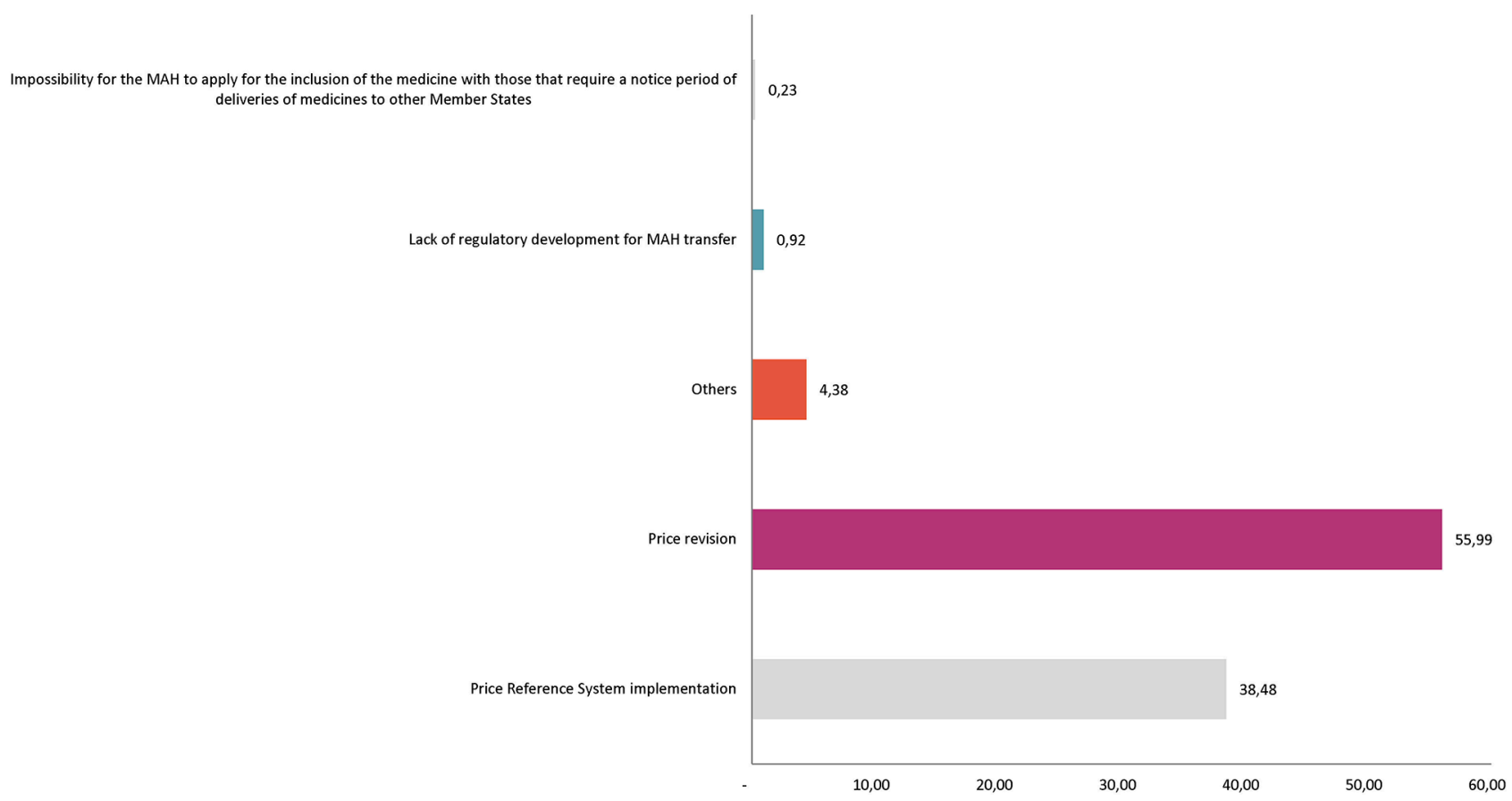

Figure 9 Main causes related to economic regulation that may lead to a possible non-permanence of medicinal products without commercial interest (reviewed list) presentations in the Spanish market. MAH, Marketing Authorisation Holders. 


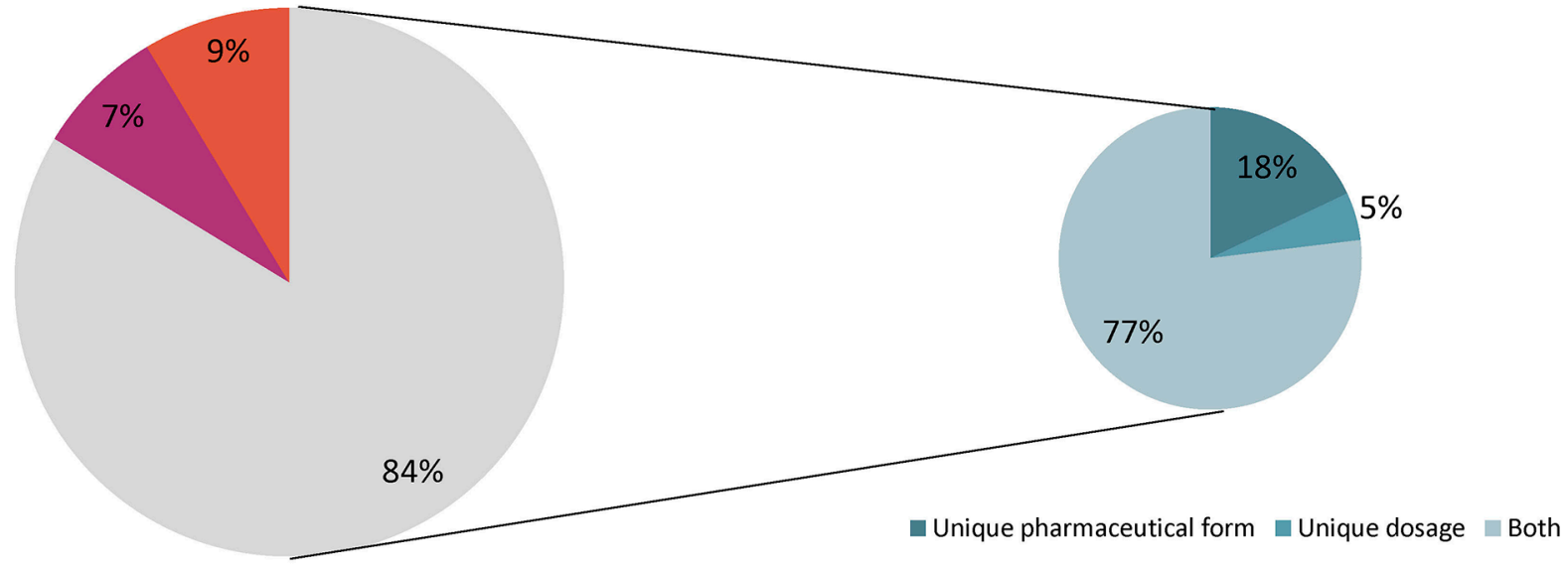

Exclusion from Price Reference System

Reducing the fall in prices through the application of weighted prices

Others

Figure 10 Main causes related to economic regulation that may lead to a possible non-permanence of the medicinal products without commercial interest submissions proposed in the Spanish market related to the Reference Price System.

in order to advance the continuity in commercialisation at a high percentage.

Regarding the upward revision of prices, the experts' stance indicates that in some cases, the increases experienced by certain affected presentations have not eliminated the threat in the continuity of these products $(7 \%)$ and in other cases $(8 \%)$ the price band of the presentations would not be of the interest to the companies (see figure 11).

Finally, the experts' contribution towards possible solutions has seen some proposals of interest to reduce the risk of lack of supply of these presentations.

The consideration of an upward revision of the price of products, for those that were approved more than 20 years ago, has been proposed (39\% responses). It also advises the modification of regulations on reference prices and allowing for certain unique presentations to

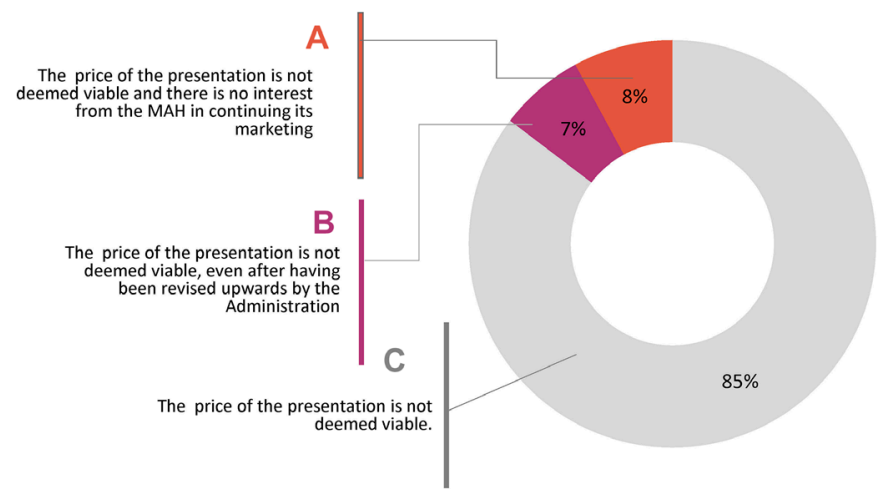

Figure 11 Main causes related to the economic regulation that may lead to a possible non-permanence of the medicinal products without commercial interest (reviewed list) presentations in the Spanish market related to the price revision. MAH, Marketing Authorisation Holders. remain outside the system ( $8 \%$ responses) or that there be a different consideration for products whose formulation and dosage have a different therapeutic focus (23\% responses).

Another aspect needing to be rectified is that, currently, some products are sold at a loss, due to the legal obligation to keep their marketing within Spain and the impossibility of withdrawing market presentations, precisely due to the refusal of AEMPS to revoke the marketing authorisation (15\% responses). Lastly, some responses mention the formal need to regulate the so-called 'therapeutic gap' to ensure that the criteria determine the obligation to keep the product on the market (15\% responses) (see figure 12).

\section{DISCUSSION}

At the time of conducting this study, the authors considered whether the category of products without commercial interest (MPWCI) that complies with Spanish legislation was, in effect, a real group of presentations of authorised and effectively marketed products, or merely just a theoretical approximation by the legislator, since the matter is still pending development.

The authors opted for the first option because, in Spain, AEMPS requires a justification from the MAH in order to suspend or stop the commercialisation of a medicine which "will accredit the specific cause (technological, scientific, economic or other reasons), as well as the estimated date of the exhaustion of stock'. ${ }^{25}$ If there are situations of sanitary interest, AEMPS can maintain the validity of the authorisation and also demand the effective commercialisation of the medication. ${ }^{3}$

Therefore, in Spain, there is a series of products that would respond to the need for special measures in relation 


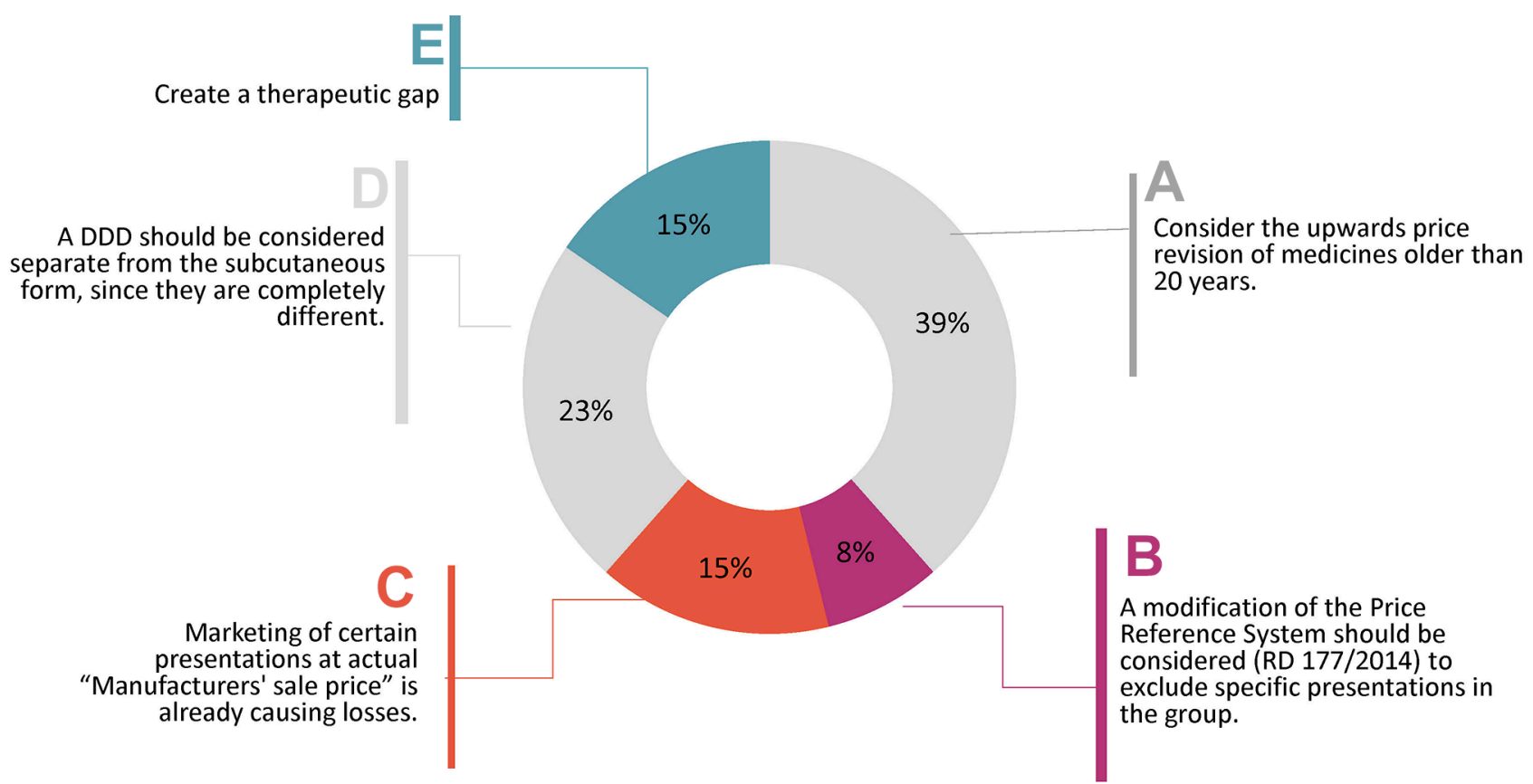

Figure 12 Main solution proposals related to economic regulation to contribute to the greater permanence of medicinal products without commercial interest presentations.

to their manufacture, import, distribution, dispensation, economic and fiscal regime to ensure their supply be considered necessary for the treatment of certain diseases or pathologies, in terms consistent with those included in article 3.3 of Royal Legislative Decree 1/2015, of July 24, which approves the revised text of the Law on guarantees and rational use of products and healthcare products.

In certain cases, lack of availability may result in a financial loss for the MAH, since the medicine is not marketed; but in other cases, the commercialisation is not viable for a longer time due to the impossibility of passing on cost increases in production (particularly in the acquisition of the active ingredients), since the price of the medicine is fixed for reimbursement reasons and price revisions are unsatisfactory, in the opinion of the experts (see figure 9).

Although this list is changing because treatments evolve over time and the commercialisation of new products turns obsolete therapies into well-established ones, there are some products that maintain their place within the therapeutic sphere despite the passage of time. This has been recognised by AEMPS who have drawn up a list of products whose disappearance would have an impact on healthcare and on patients.

Despite the fact that European legislation has established the centralised procedure as a single procedure to achieve the commercialisation of a medicine throughout the EU and that there are incentives for micro, small or medium-sized companies or other kind of aids that contribute to obtaining the authorisation to market certain types of medicines, such as orphan medicines, ${ }^{26}$ the medicines analysed have a marketing authorisation granted previously to those provisions (see figure 7). In fact, of the 568 presentations studied, only $30(5.28 \%)$ have been authorised by centralised procedure.
As noted, the legislation in force in Spain regulates a figure, which authorises the competent authority to not grant the temporary suspension, or the revocation of the marketing authorisation of a product 'when there are health reasons or healthcare interest, as in the case if a therapeutic gap is created, whether in the market in general or in the pharmaceutical provision of the National Health System, the Spanish Agency of Products and Medical Devices will maintain the validity of the authorisation and demand the effective commercialization of the medication. ${ }^{, 7}$

The figure of the therapeutic gap envisaged in the Spanish regulations in which it is considered a very serious infringement for 'the marketing authorisation holder to cease the supply of a medicinal product in the event that there are health reasons or healthcare interest, for example if there were a therapeutic gap, either in the market in general or in the pharmaceutical provision of the National Health System, ${ }^{4}$ has not prevented the discontinuation of the marketing of certain products when the holder has perceived them no longer viable for the Spanish market. The therapeutic gap figure does not have an explicit 'fit' within the EU legislation, which for the discontinuation of commercialization (temporary or permanent) requires that the MAH inform the competent authorities within a 2-month period. The aim of the MAH is to try to maintain the supply, in order to avoid the discontinuation of commercialization in Spain; in some cases, however, this is not so and AEMPS has had to justify the acquisition of certain products through foreign medication. ${ }^{27}$

In short, both the positive list from AEMPS and the possibility of stating that the exclusion or revocation of the marketing authorisation of a certain product would 
create a therapeutic gap point to the need to consolidate a group of products with special characteristics, which should carry MPWCI conditions.

Membership under proposed MPWCI status has also been endorsed by a group of experts from the companies associated to Farmaindustria who have found themselves obligated to maintain the effective commercialisation of these products, given the absence of others with the same composition and taking into consideration the role in which the product has in therapeutics.

However, the price erosion that occurs with the proposed MPWCIs and the absence of measures that protect them from technical and economic regulations may lead to a gradual lack of supply for any of these products. Not only does this lack of regulation diminish the authorised treatment options, but it also discourages the presentation of new pharmaceutical form innovations intended for the unmet medical needs that are of interest to patients, healthcare professionals, administrations and industry.

It seems clear that the regulations that regulate certain matters such as reference prices or future serialisation may contribute to the lack of viability in continuing marketing certain presentations without competition (despite their protection rights having expired). Also, the lack of protection for these strategic presentations makes it difficult to not carry out initiatives to commercialise innovations of these known products, since they would also be negatively affected by said regulation. ${ }^{28}$

The Directorate General of Basic Healthcare Services Portfolio and Pharmacy (DGCBSF) mentions that it is working on the modification of the legislation to avoid that 'the purely mathematical mechanisms of the Reference Price System may exert perverse effects and provoke the departure of the pharmaceutical supply of medicinal products of proven therapeutic efficacy.'

For its part, AEMPS has considered within the Plan for Guarantees of Medicinal Product Supply that one of the measures aimed at preventing supply problems is the identification of products at risk, whose shortage could have a welfare impact, for the purpose of adopting specific preventative measures. ${ }^{29}$

One school of thought is that because these products are not new chemical entities, they should not be very expensive, because drug companies would have made profits from their initial marketing phases. In fact, generally speaking, it is true that the medicine cycle determines that the main return of the investment made in $R \& D$ is made in the initial phases since, once the protection of the original medicine is completed, a necessary and progressive price erosion occurs of the original medicines for the entry of generic and biosimilar medicines.

The authors consider that the case of MPWCI medicines would be different. MPWCI medicines have been licensed for many years and, despite lack of protection, they do not always have generic competitors or other brands. In these circumstances, the attraction to market these medicines is low, due to the sum of several factors:
(1) MPWCI prices are not attractive enough (since they have not increased or have been reduced because they are affected by reference prices), (2) the small volume of units that are commercialised, (3) the difficulties in maintaining the medicinal product on the market due to a regulatory or manufacturing reasons, including the problems for obtaining certain active ingredients, and (4) the poor prioritisation of these products in the overall strategy of a certain company.

For this reason, as has been done with the regulation of another category of medicines, such as orphan medicines ${ }^{30}$ and paediatric medicines, ${ }^{31}$ the competent authorities could establish MPWCI qualification procedures to avoid stock-outs in certain member states, encourage the permanence of these medicines in the EU and contribute to the adoption of measures that, without destabilising public health systems, avoid the shift of prescription to more expensive alternatives.

\section{CONCLUSIONS}

In short, the following conclusions can be drawn from the study carried out:

1. This work can be considered as the first study that establishes a perimeter of products presented as MPWCI. From the original AEMPS list, a further list of affected active substances has been identified with the contributions of a significant number of experts from pharmaceutical companies associated to Farmaindustria.

2. As the results show, the products proposed as MPWCI are old and are developed by active substances of chemical origin, parenterally administered much more frequently than the rest of the general market. Unlike oral forms, injectable forms require adequate manufacturing facilities to guarantee the quality and sterility of the product, which naturally increases the cost of the product and if the price is low or obsolete, the pharmaceutical form can also be used to decrease the viability in order to maintain the marketing of these presentations.

3. As shown in the results, an upward revision of prices is necessary to contribute to the permanence in the market of these presentations. On the other hand, the experts of the companies have not valued the current price revisions as a sufficiently satisfactory mechanism to change the consideration of these products with respect to the interest on the part of some MAHs to maintain the future commercialisation of these presentations.

4. The RPS is currently regulated and does not benefit the permanence in the market of products proposed as MPWCI, since some presentations without competition in the market suffer from regular price erosion with the successive annual updates of the system, generating a situation of unfeasibility for commercialisation, which implies an insufficiency in the supply or the effective disappearance of the market. 
5. It seems necessary to develop a regulation that protects the products proposed as MPWCI while maintaining the conditions of the absence of alternatives and therapeutic relevance for patients. This regulation should establish that the formal consideration of MPWCI allows the review of the price of the product until its viability is guaranteed in the commercialisation and the exclusion of the RPS, in the event that the absence of a competitor could jeopardise the continued supply of the medicine.

Acknowledgements We wish to give special thanks to those companies that contributed to the survey and to Farmaindustria's staff also.

Contributors EES wrote the paper, FMB processed the data and built up the figures after conducting the survey, JMSN and EBP reviewed from an academic point of view the whole paper.

Funding The authors have not declared a specific grant for this research from any funding agency in the public, commercial or not-for-profit sectors.

Competing interests None declared.

Patient consent for publication Not required.

Provenance and peer review Not commissioned; externally peer reviewed.

Data sharing statement For further information please contact the author.

Open access This is an open access article distributed in accordance with the Creative Commons Attribution Non Commercial (CC BY-NC 4.0) license, which permits others to distribute, remix, adapt, build upon this work non-commercially, and license their derivative works on different terms, provided the original work is properly cited, appropriate credit is given, any changes made indicated, and the use is non-commercial. See: http://creativecommons.org/licenses/by-nc/4.0/.

\section{REFERENCES}

1. Official Journal of the European Union. Commission Delegated Regulation (EU) No 2016/161 of 2 October 2015 supplementing Directive 2001/83/EC of the European Parliament and of the Council by laying down detailed rules for the safety features appearing on the packaging of medicinal products for human use. 2016:1-12.

2. Official State Gazette (BOE). Royal Decree 577/2013, of July 26, laying down rules for pharmacovigilance of medicinal products for human use. BOE no. 179. 2013.

3. Official State Gazette (BOE). Royal Decree 177/2014, of March 21, laying down the Price Rference System and Homogenous Groups regulations for medicines within the National Health System, and certain information systems regarding financing and prices of medicines and medical devices. BOE no. 73. 2014.

4. Official State Gazette (BOE). Royal Decree-Law 1/2015, of July 24th, which approves the text of the law of guarantees and rational use of medicines and medical devices. BOE no. 177. 2015.

5. Official Journal of the European Union. Regulation (EC) No 726/2004 of the European Parliament and of the Council of 31 March 2004 laying down Community procedures for the authorisation and supervision of medicinal products for human and veterinary use and establishing a European Medicines Agency. 2004.

6. Official Journal of the European Union. Directive 2001/83/EC of the European Parliament and of the Council of 6 November 2001 on the Community code relating to medicinal products for human use. 2001.

7. Official State Gazette (BOE). Royal Decree-Law 1345/2007, of October 11, laying down the authorisation, register and dispensing conditions of human medicines manufactured by industry; BOE no. 267. 2007.

8. Official State Gazette (BOE). Royal Decree 485/2017, of May 12, laying down the basic organic structure of Ministry of Health. BOE no. 114. 2017:39657-80.

9. Rojo A, Polanco A. Acceso al mercado de los fármacos innovadores financiados por el Sistema Nacional de Salud. Farm Abierta 2012;26:2-5.
10. Pérez G, Santos SP, Pajuelo MG, et al. "Organización y funcionamiento de los Comités Autonómicos de Evaluación de medicamentos". Madrid: Agencia de Evaluación de Tecnologías Sanitarias - Instituto de Salud Carlos III:Monograph. 2014. http:// gesdoc.isciii.es/gesdoccontroller?action=download\&id=02/10/20144 a73cebe24

11. Miller KL. Do investors value the FDA orphan drug designation? Orphanet J Rare Dis 2017;12:12:1.

12. Gilabert-Perramon A, Torrent-Farnell J, Catalan A, et al. HT5 Development of a Multi-Criteria Decision Analysis (MCDA) Framework for health care decision-making in catalonia (spain): pilot study focused in orphan drugs. Value in Health 2016;19:A353.

13. Spanish Agency of Medicinal Products and Devices website. Online Medicine Information Centre-AEMPS. 2017 https://cima.aemps.es/ cima/publico/home.html.

14. Court of Auditors. Ministry of health's Annual Activity Report related to pharmaceutical area, years 2014 and 2015. 2016.

15. Boshnakova A. Cancer medicines shortages in Europe. Policy recommendations to prevent and manage shortages: The Economist, 2017.

16. Vaccines Europe. From vaccines shortages to sustainable vaccine supply; Vaccines Europe Position. VE 29.04.16. 2016.

17. Gloor C, Dantés M, Graefenhain E, et al. An Evaluation of Medicines Shortages in Europe with more in-depth review of these in France, Greece, Poland, Spain and the United Kingdom. 68: birglißag, 2013.

18. EMA Report. Developing a proactive approach to the prevention of medicines shortages due to manufacturing and quality problems. 2015.

19. Esteve E. Aspectos clave de la regulación española sobre serialización de medicamentos: PharmaTech, 2017.

20. Official State Gazette (BOE). Royal Decree-Law 9/2011, of August 19 , laying down the measures for improving quality and cohesion of the National health System, contribution to fiscal consolidation, and increase of maximum amount of State guarantees for 2011. BOE no. 315. 2011 https://doi.org/.

21. Information of Homogeneous Group and voluntary price reductions' applications. Royal Decree-Law 16/2012 implementation. 2017. https://www.msssi.gob.es/profesionales/farmacia/PreciosMasBajos/ home.htm

22. Esteve Sala E. Modificación del sistema de precios de referencia en España en la conformación de los conjuntos. Lecciones aprendidas y reformas pendientes. Cuad Derecho Farm 2014;51:22-35.

23. IQVIA. IQVIA DataBase. 2017. https://www.iqvia.com/

24. Spanish Medicine and Products Devices Agency. Circular No 2/2012, related to exceptional prior notification in order to be sent to another Member State. 2017. https://www.aemps.gob.es/informa/circulares/ medicamentosUsoHumano/2012/home.htm

25. Spanish Medicine and Products Devices Agency. Circular No 3/2011, related to Information to be provided by notifications of temporary suspension or cessation of marketing (revocation) of a medicine at the request of the holder of the authorization as well as in relation to supply problems that may arise. 2018. https://www.aemps.gob.es/ informa/circulares/medicamentosUsoHumano/2011/docs/circular_ 03-2011_susp-temp-comerc.pdf

26. European Medicines Agency. Explanatory note on general fees payable to the European Medicines Agency. EMA/57364/2018. Chapters 5.1 and 5.2. 2018. http://www.ema.europa.eu/docs/en_GB/ document_library/Other/2018/03/WC500246428.pdf

27. AEMPS. Informative Note "Supply of medicines in exceptional circumstances such as certain citostatics belonging to Aspen Pharma Trading Ltd". 2014.

28. Sleigh SH, Barton CL. Repurposing Strategies for Therapeutics. Pharmaceut Med 2010;24:151-9.

29. Activity Report of AEMPS 2016. 2017. https://wwzzw.aemps.gob.es/ laAEMPS/memoria/home.htm

30. Official Journal of the European Union. Regulation (EC) No. 141/2000 of the European Parliament and of the Council of 16 December 1999 on Orphan Medicinal Products. 2000.

31. Official Journal of the European Union. Regulation (EC) No. 1901/2006 of the European Parliament and of the Council of 12 December 2006 on Medicinal Products for Paediatric Use and amending Regulation (EC) No 1768/92, Directive 2001/20/EC, Directive 2001/83/EC and Regulation (EC) No 726/2004 (Official Journal of the European Union I 378/1, 27.12.2006). Official Journal of the European Union 2006. 